\title{
Becoming Historic: Unsettling Preservation as "Activism" in the Memphis Neighborhood of Central Gardens
}

Leslee Bailey-Tarbett, lktrbett@memphis.edu

\begin{abstract}
Based on an interdisciplinary research course for graduate students, this paper describes a project that combines arts-based research, walking methodology, and posthuman theories to design a researchcreation. The purpose of this assemblage of photographs, archived newsletters, online information, maps, and other materials is to aid in the suspension of linear thinking and offer a unique contribution to the discussion of what gaining "historic" status can do in a particular place/time. This paper describes how the neighborhood association, formed 50 years ago, had the primary mission to lobby for historic status in order to protect property values and prevent multi-dwelling homes and businesses from moving in. By embarking on a multisensory inquiry employing walking methodology, I demonstrate how this insular, exclusive, historic neighborhood continues to be entangled within the surrounding geographic areas, as well as within the socio-politico-and economic dimensions of the city.
\end{abstract}

Keywords: postqualitative, walking methodology, posthuman

In the fall of 2017, the city of Memphis was preparing for the $50^{\text {th }}$ anniversary of the assassination of $\mathrm{Dr}$. Martin Luther King Jr. The National Civil Rights Museum, along with partner organizations, engaged in a year-long commemoration of Dr. King's life and legacy. The events of the year were focused on the theme, MLK50, Where do we go from here?, honoring Dr. King as a leader in the Civil Rights Movement while activating social change for the future.

It was during this time that we came together from different graduate programs at the University of Memphis and Memphis College of Art to begin our exploration of (Dis)placed Bodies, those unjustly pushed out of housing, employment, and educational opportunities due to structural racism and discrimination. Across institutions and disciplines, we began to unlearn the rigid separation of writing, philosophy, and art in order to recognize an "ethico-political responsibility" (Springgay \& Truman, 2017, 
p. 1) in "the process of thinking-doing" (Manning, 2016, p. 42) research. We began to embrace an interconnected and embodied view of research that values creation and art-making as politically active and transformative inquiry.

In what follows, I share how research-creation and walking methodology, grounded in posthuman theories, aided in the suspension of linear thinking to offer a unique understanding of what gaining "historic" status can do in a particular place-time. First, I describe how our course readings guided my conceptualization of walking methodology as embodied and oriented toward social justice and activism. Next, I share how embarking on this multisensory inquiry generated curiosity, depth, and space to work frictionally and productively with the concepts of activism, (dis)placement, and preservation. I describe my final project, a mixed-media layered collage that demonstrates the entangled nature of the past, present, and future. This piece makes visible racist notions of preservation and illuminates how silence and preservation discourses can disguise injustice. Finally, I imagine how walking research and researchcreation are propositional, propelling my thinking into other dimensions of the city.

\section{The Process of Thinking-Doing Together}

When I learned that Dr. Nordstrom was designing an arts-based course in which students would explore walking methodology and research-creation, I did not know what that would entail. However, I knew it would be consistent with how she guides innovative research inquiry in her other courses. I knew that it would expand my understandings of postqualitative research and would open up new possibilities. Nordstrom and Ulmer (2017) illustrate how engaging in this type of inquiry can be multiple, communal, and generative of new knowledges.

[W] hat we are doing here: finding many ways of walking down to the river from where we live-in this case, our current intellectual residence in postqualitative inquiry. We may take different paths as we approach the river, and we also may enter and exit at different locations at different points in time. But we are, in these ways, walking together... Although we do not claim to understand-for we are also still trying to think things out-we continue to think and do together (p. 1).

So, that is what we, as a group, did: We read, we walked, we wrote, we thought, we made things, not necessarily in that order, and sometimes all at once.

In our initial discussions of walking research and research-creation, class members questioned how to navigate academia's narrow, prescriptive structures while still allowing for the experimentation with creations that were still to come. Erin Manning's (2016) chapter, Against Method, gave insight into how research-creation might challenge current conceptualizations of research and methodology. It "creates the conditions for new ways of encountering study - forms and forces of intellectuality that cut across normative accounts of what it means to know" (p. 27). We wrestled with this concept of creation; most, if not all of us, were accustomed to detailed guidelines of acceptable work. Not knowing the exact details and expectations of the project induced fear and panic. Not knowing the final outcome exposed 
our own firm grip on prescriptive research methods and methodologies. How would we know if we were doing it right? What would we write? What would we create?

In order for us to engage in the process of research-creation, we had to allow for a period of not knowing the answers to those questions and many others. Here is what we did not know: What is walking research? How will walking produce new knowledge? How will Barad, Haraway, Manning, Nordstrom, Springgay and Truman, Ulmer, etc. help us think differently about a Memphis neighborhood? How does this all connect with injustice, inequality, MLK50, and (Dis)placed Bodies? Where do we begin?

According to Manning (2016), "[T]he unquantifiable within experience can only be taken into account if we begin with a mode of inquiry that refutes initial categorization...radical empiricism begins in the midst, in the mess of relations" (p. 29). When we categorize, we limit. When we employ prescriptive methods, we inhibit the not-yet known. This period of not knowing allowed me to conceptualize the unstable sensation that I felt walking without explicit directions. We don't generally talk about not knowing, but instead we refer to when we will know and how quickly we can get there. The course readings provided space to explore what could be produced together through thinking-doing (Manning, 2016). Reading was our entry point into a postqualitative understanding of theory and research methodology.

Postqualitative methodology is a "journey without a clear beginning or ending point and a journey with multiple paths to be taken" (Koro-Ljungberg, 2016, p. 3). Postqualitative research is in the doing. It is a messy process, a becoming. Walking methodology, grounded in the posts, then, is not simply a means to an end, but an active component of what the study will produce. This shift from methodology in a conventional paradigm to a postqualitative view is a "re-imagining of what method might do, rather than what it is or how to do it." (St. Pierre, et al., 2016, p. 105). We engaged in walking with the understanding that we would encounter new ideas and critical perspectives in the act of moving and thinking in a Memphis neighborhood. "We walk[ed] with, as well as within, the environment perceived relationally" (Manning, 2009, p. 49). In other words, the neighborhood, all the living and nonliving elements was active and generative. Walking with the neighborhood meant opening up new ways of understanding method and data.

Springgay \& Truman (2018) reconceptualize walking methodology as a way to disrupt privileged and normalized understandings, decentering the human in the process. By reimagining walking methodology, not as an individual experience, but as a production of interconnected elements, human and non-human, creating a particular moment, "properties are no longer embedded in individuals but emergent features of entangled productions" (Truman and Springgay, 2016, p. 261). Walking is a process of emerging and becoming with humans and non-humans through events. Walking methodology offers a way to explore data "through our engagement in materials and the materiality" (Waterhouse, Otterstad, \& Jensen, 2016, p. 202).

To guide and focus the walks, I drew upon Truman \& Springgay's (2016) notion of “propositional 
thinking" in relation to walking research (p. 259). Propositions are speculative and suggestive, offering ideas of what could happen in an event. They are at the same time co-constitutive within the event (Truman \& Springgay, 2016). Instead of viewing walking as a habitual movement or simply embodying a space, propositional thinking helps to envision walking as becoming through the entangled production of events. "When walking is understood as a proposition, subjects are not given to experiencing movement, space, walking, etc. in any pre-determined way. Walking becomes stripped of its own assumptions" (Truman \& Springgay, 2016, p. 259). The propositions do not pre-determine what will happen during a walk, but instead offer possibilities and things to consider while moving, thinking, and sensing a space.

\section{Walking As An Archive}

While walking through Central Gardens, I experienced time and space in different ways. At one point, I walked slowly down Belvedere Boulevard, the widest, most prominent thoroughfare of the neighborhood. Under the canopy of Southern Magnolias and English Oaks, I tried to be inside my bodythat is, I tried to stay present and engage my senses, noticing how my body intra-acted relationally with the environment. I read the historical markers and I imagined what this street might have looked like in the early $20^{\text {th }}$ century, when the development began. According to the plaque, Central Gardens, now a historic district, began as a home to Memphis' most prominent citizens.

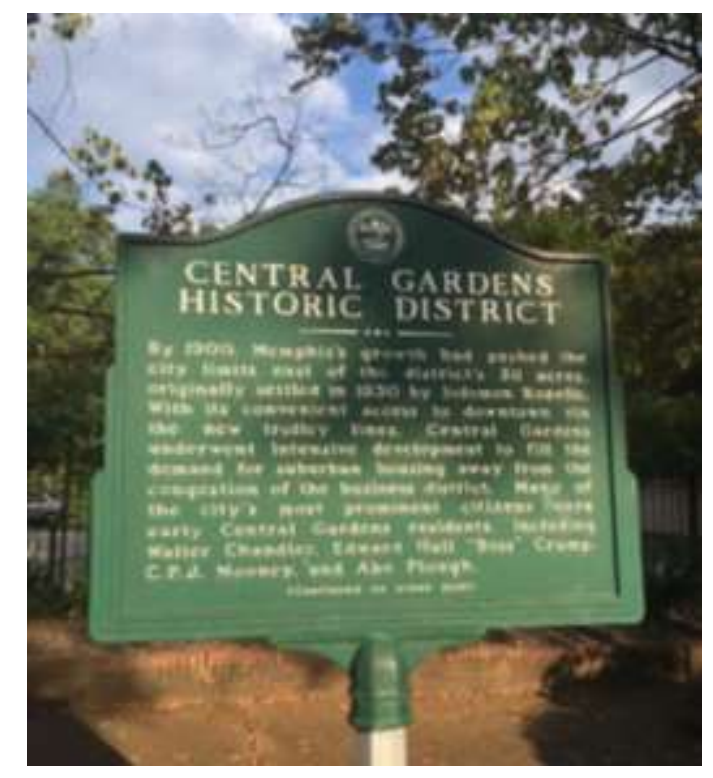

Figure 1. Central Gardens historic district marker.

I found Truman and Springgay's (2016) proposition: walking like an archive a helpful guide walking through the predominantly white, upper-class, Memphis neighborhood of Central Gardens. The traditional concept of archive as a collection of historical information is unsettled. Instead of inert files filled with old documents, the walker is understood as actively enmeshed in the past, present, and imagined futures simultaneously. This proposition helped me to think about time as multiple and unstable, not in the linear way we often refer to events. Temporality, or our relationship with time, is 
complicated and entangled. Adopting this conceptualization of time and walking as an archive with the neighborhood produced a sense of tangled oneness with the place and history, which had been an entirely unfamiliar site before the course.

Though I tried to concentrate on how my body moved through the space, I was also lost in thinking of the past, the histories of the place. Who lived in this neighborhood? Who was excluded from living here? The echoes of the past traversed the present moment as I walked from home to home, breathing the humid air. The emerging of events, through time and space, made me question the history of a space deemed historic.

On another day, I walked with two other students and my dog (a six-month-old Collie puppy). He was excited, so our steps were quick. We hurried through part of the neighborhood where homes were closer to the street. There were Halloween decorations, children riding bikes, and people working in their yards. The people we encountered said hello and walked toward us to pet Murray or ask us about him. This walk was a whirlwind and led me to consider how differently and how quickly our walk progressed, how the sensation was a flurry for the senses, yet one where I felt entirely present in my body.

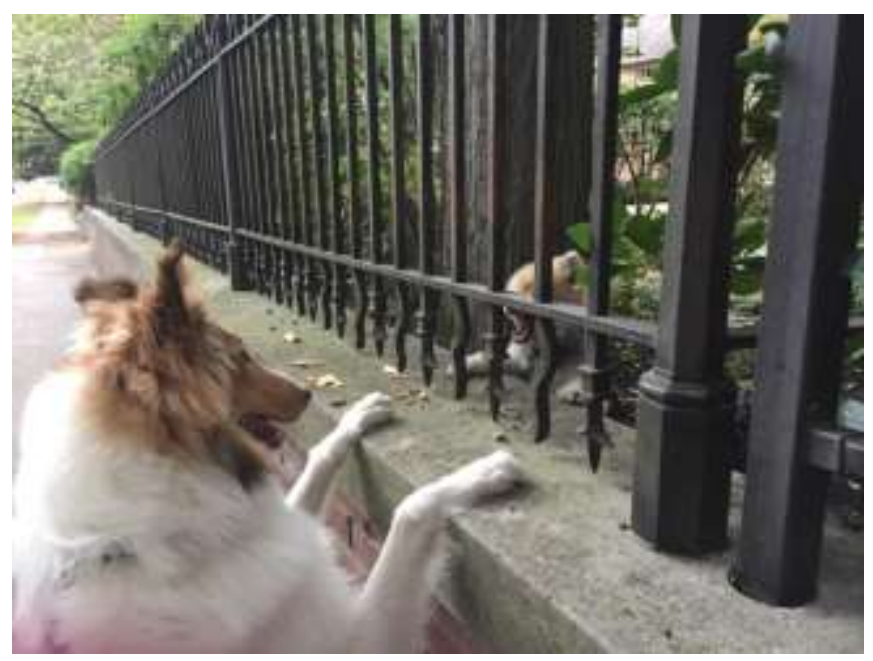

Figure 2. Walking-with Murray the dog.

Following that walk, I recalled Haraway's term the Chthulucene, which describes time and space as entangled, "full inheritances, of remembering, and full of comings or nurturing that might still be" (p. 3) with "the sense of thick, ongoing presence...infusing all sorts of temporalities and materialities" (p. 3). This culminated in a richer understanding of how we can experience the present, and at the same time exist within and among a space that soaked with history, power, and echoes of the past. From walking in Central Gardens, I became curious about how this neighborhood became the "historic" neighborhood that it is today. What was the connection to this neighborhood and the racial and economic history of the city of Memphis? Who had been or was currently being (dis)placed from this place?

Walking like an archive helped me conceptualize myself, not just as a body, but as a living, walking 
record of memories, and connections- being formed and reformed through the events. When I read on the neighborhood's website that the Central Gardens neighborhood association was "born out of activism" (Fleischer, 2017) which brought more questions about the nature of the activism. When I pressed my hand against the bronze markers that designated the boundaries of the neighborhood, it registered in my body. By physically walking the boundaries of the space and encountering invoking the word "activism" on the website, I wanted to know how these two moments intersected. The neighborhood association's website provided insight into how the neighborhood association's activist goals were aligned with achieving historic status.

In the fall of 1975 Central Gardens' residents were sitting on the edge of their collective seats in waiting for the Memphis City Council and the Planning Commission to vote on neighborhood zoning changes...critical to preserving the small-town and family-oriented integrity of the neighborhood...The decision gave residents the boost they desired to continue spreading the "fix-up" attitude throughout the neighborhood and through the 1970s. Combined with the support from the city, the upward trends and excitement of old house renovations brought more new buyers into Central Gardens, an influx not seen since the 1920s, that rejuvenated the neighborhood. The renaissance brought in "middle to upper class people who represented a variety of professions - attorneys, artists, architects, teachers, bankers, politicians, and musicians. A new generation of politically influential citizens made Central Gardens its base camp" (Fleischer, 2017).

The Central Gardens Neighborhood Association pressed forward to gain historic status for their neighborhood to protect it from what they saw as inevitable deterioration and blight.

I was able to access the neighborhood association's monthly newsletters, spanning fifty years, through the Memphis Public Library. Working with the text and the images from the Central Gardens newsletters was haunting. The silence about the Civil Rights Movement and social justice issues were absent from the authors' narratives. There were many references to zoning and security but without any explicit political or racial language. Gaining historical status became a means to an end to control what bodies may live in this space and how policies could enforce the future security from outside change. Historic status gave power to the association to prevent what they deemed as "undesirables" from moving in and a subtle discourse of othering and segregation.

Haraway's (2016) words resonated deeply with me while reading the neighborhood association's newsletters of the last fifty years. Haraway writes, "In urgent times, many of us are tempted to address trouble in terms of making an imagined future safe, of stopping something from happening that looms in the future, of clearing away the present and the past in order to make futures for coming generations" (p. 1). Reading the residents' fears through the decades and their attempts to preserve the neighborhood that they wanted to keep safe for future generations illuminated how our imagined futures entangle with the past and with our thick present. 


\section{Research-Creation}

Becoming with the data was a distinctly different orientation to research than conventional qualitative methods and analysis. Posthuman theories emphasize interconnection with our environments, a significant departure from a traditional human-centered approach to research which privileges language (Ulmer, 2017). Posthumanism offers a framework in which to engage with the phenomena differently and consider how factors such as affect, materiality, place, time, and power operate simultaneously. Posthumanism allows research to start in a different place, outside the human subject, acknowledging the potential for new ways of seeing and new ways of questioning (Ulmer, 2017).

Ulmer critiques the notion that language can fully represent the complexity inherent in our world. "Language - whether it be in the forms of texts, sounds, or images - insufficiently represents the interactions among society, culture, geology, and ecology" (Ulmer, 2017, p. 3). In other words, language, which is human-centered and often privileged in research, is unable to fully represent the intricate connections and entanglement within our world.

The following is an excerpt from my class blog, where I wrote about the entanglement of readings, theories, and bodily experiences from the walks. Here I conceptualize how walking and reading created new ways of thinking about data.

Data is not limited to the walks, but includes newsletters, course readings, class discussions, notes, doodles, newspaper clippings, and photographs. I am inventing, performing, and exploring the data...and becoming data as I am affected by what I am doing, feeling, seeing, and touching. I feel myself becoming with the materials-and it feels messy and risky-and honest. It's invigorating to be/becoming with the data in a way that I have not yet experienced with other projects. The possibilities of engaging in research in this way opens up the space to experience creation, invention, and assemblage in a way that will allow me to think in ways not available to me before. It is vulnerable and requires trust and devotion in the process and in the entanglement of myself and other data to become with me (Class Blog, October 2017).

Creating with data allowed my project to slowly take shape through the process of not knowing to thinking-with to creating-with. I became with the data and transformed understandings of place and time became data. The slow process of writing and walking and staying with the trouble changed my understanding of research.

My research-creation is a mixed-media collage on plexiglass (see Figure 1). The photographs and neighborhood association newsletters were printed on transparencies, so they may be viewed adjacent to and through the photographs of my walks through the Memphis neighborhood of Central Gardens. I chose to layer the transparent plexiglass, depicting the text and images as entangled and diffractive. The piece was suspended from two wires and appeared to be floating above the white staircase of Rust Hall, at the Memphis College of Arts where our projects were displayed for the (Dis)placed Bodies Exhibition. 
As we walked through the exhibit, a powerful thought took up residence in my mind: The researchcreations are us, and we are the research-creations. By becoming-with the data and materials, were able to see ourselves as part of the entangled production of our projects, of the course, and of the city.

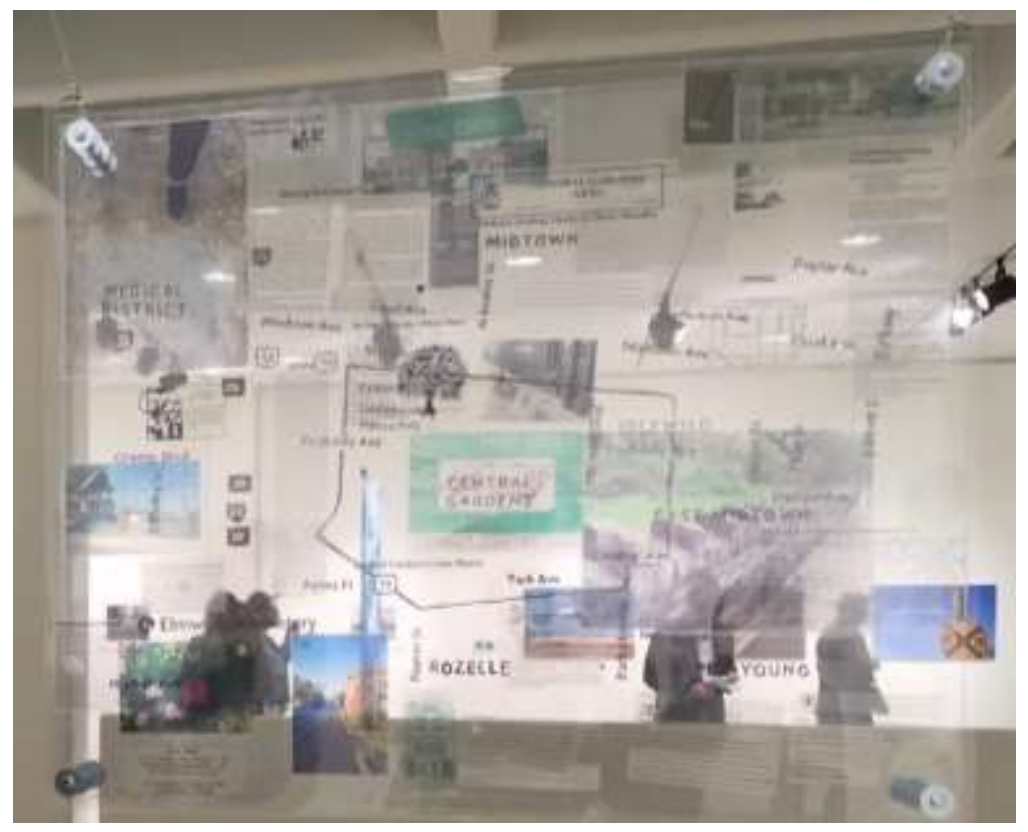

Figure 3. Becoming historic, mixed-media collage on layered plexiglass, (Dis)placed Bodies Exhibition at Rust Hall, Memphis College of Art, Memphis, TN., January 30, 2018.

\section{Unsettling Preservation as Activism}

After the final class, the process of thinking-doing continued. When I found myself in Central Gardens or any "historic" site, I was aware of myself as an archive, carrying stories and affects from the past. Memphis, like many southern cities at the time, were having fierce debates over the removal of two confederate monuments. One monument, residing in a small urban park, was a century-old bronze statue of Nathan Bedford Forrest, the first grand wizard of the Ku Klux Klan. The other, a large equestrian statue of Confederate President Jefferson Davis, overlooking the Mississippi River Park. Echoes from the Central Gardens newsletters and walks reminded me of the complex political and economic power inherent in an activism of preservation.

In December of 2017, the statues were removed despite the Tennessee Heritage Protection Act, enacted in 2013, which prohibits the removal, renaming, or the relocation of a memorial. In order to circumvent this state law, a local nonprofit organization worked with city leaders to purchase the park (Blake, 2018). The removal of the statues from private property provided a legal loophole that made the decision possible (Yellin \& Fausset, 2017).

I now understand this protection act, like the quest for historic status much differently than before I walked the neighborhood of Central Gardens. Thinking propositionally, walking like an archive, 
produced a unique orientation to history. Art, writing, philosophy, and research worked together to disrupt the normalized understandings of what preservation and activism can mean in a particular time and place. Instead, feet moving against the pavement provoked me to ask why this space is valued over another space. Images and text from Central Garden's neighborhood association's newsletters raised this question in the face of historic preservation: How does nostalgia for the past and fear for the future shape systemic racism and discrimination in the name of activism? Taken-for-granted notions of preserving history became unsettled.

I began in an unfamiliar and uncomfortable place, the space of "not knowing". Not knowing and walking like an archive (Truman \& Springgay, 2016), demonstrated our unstable understandings of history. The historic was and is always entangled with the political and economic powers of a place and time. The ideation of "the good old days" is a powerful and dangerous myth, but one that often goes unchallenged.

Truman and Springgay (2018) address how a materialist ontology that "recognizes the interconnections of all phenomena where matter is indeterminate, constantly forming and reforming" (p. 7) needs a new understanding of ethics and accountability that "unsettle norms, and call attention to how sexuality, gender, and race are constituted and regulated by hierarchies of humanness" (p. 7). Orienting research by first disrupting long-held, taken-for-granted assumptions is central to post-qualitative work. Interrogating normalized and conventional values and methods are essential for the creation of work yet to come. Our engagement with walking, as a practice to unsettle normalized understandings of research and ethics was one that produced surprising and generative results.

\section{References}

Barad, K. (2007). Meeting the universe halfway: Quantum physics and the entanglement of matter and meaning. Durham, NC: Duke University Press. https://doi.org/10.1215/9780822388128

Blake, A. (2018). Memphis sued over removal of statue from grave of KKK leader Nathan Bedford Forrest. The Washington Times. Retrieved from https://www.washingtontimes.com/news/2018/dec/19/memphis-sued-over-removal-statuegrave-first-kkk-1/

Deleuze, G., \& Guattari, F. (1987). A thousand plateaus: Capitalism and schizophrenia. (B. Massumi, Trans.). Minneapolis, MN: University of Minnesota Press.

Fleisher, M. (2017). An association born out of activism: Part 2. Retrieved from https://www.centralgardens.org/part-2--central-gardens---

Haraway, D. J. (2016). Staying with the trouble: Making kin in the Chthulucene. Durham, NC: Duke University Press. https://doi.org/10.1215/9780822373780

Jackson, A., \& Mazzei, L. (2012). Thinking with theory in qualitative research: Viewing data across multiple perspectives. New York, NY: Routledge.

Manning, E. (2009). Relationscapes: Movement, art, philosophy. Cambridge, MA: The MIT Press. https://doi.org/10.7551/mitpress/9780262134903.001.0001 
Manning, E. (2016). The minor gesture. Durham, NC: Duke University Press.

Nordstrom, S., \& Ulmer, J. (2017). Postqualitative curations and creations. Reconceptualizing Educational Research Methodology, 8(3), 1-15.

Springgay, S., \& Truman, S. E. (2017). A transmaterial approach to walking methodologies: Embodiment, affect, and a sonic art performance. Body \& Society, 23(4), 27-58. https://doi.org/10.1177/1357034X17732626

Truman, S., \& Springgay, S. (2016). Propositions for walking research. In Burnard, P., Mackinlay, E., \& Powell, K. (Eds.), The Routledge international handbook of intercultural arts research, (259-267). New York, NY: Routledge.

Ulmer, J. B. (2017). Writing slow ontology. Qualitative Inquiry, 23(3), 201-211. https://doi.org/10.1177/1077800416643994

Waterhouse, A. H. L., Otterstad, A. M., \& Jensen, M. (2016). ... anything but synchronized swimming/methodologies... artistic movements in/with unknown inventions. Qualitative Inquiry, 22(3), 201-209.

Yellin, E., \& Fausset, R. (2017). How Memphis hopes to move on, now that statues are down. New York Times. Retrieved from https://www.nytimes.com/2017/12/21/us/memphis-confederate-statues-parks.html 